\title{
MERCADOS DA AGRICULTURA FAMILIAR NO SUL DE MINAS GERAIS
}

\author{
César Buno Favarão ${ }^{1}$, Artur Leonardo Andrade e Flamarion Dutra Alves $^{3}$
}

${ }^{1}$ Graduação em Geografia-Bacharelado, membro do Grupo de Estudos Regionais e Socioespaciais-GERES/Universidade Federal de Alfenas-MG. Bolsista Iniciação Científica COPESQ-PAIRD/UNIFAL-MG. cesar_unifal08@yahoo.com.br

${ }^{2}$ Graduação em Geografia-Bacharelado, membro do Grupo de Estudos Regionais e Socioespaciais-GERES/ Universidade Federal de Alfenas-MG. Bolsista Iniciação Científica FAPEMIG. leonardoxala@yahoo.com.br

${ }^{3}$ Professor Doutor do Curso de Geografia e líder do Grupo de Estudos Regionais e Socioespaciais-GERES/ Universidade Federal de Alfenas-MG. dutrasm@yahoo.com.br

\begin{abstract}
Resumo - A pesquisa tem como objetivo caracterizar diferentes realidades da agricultura familiar, práticas agroecológicas e mercados no Sul de Minas Gerais. Foram estudados dois agentes de desenvolvimento socioeconômico na região. Primeiro a Feira Livre Semanal na cidade de Alfenas - MG, que conta com 516 feirantes da região sul de Minas, e a produção agroecológica e convencional no Assentamento Primeiro do Sul, no município de Campo do Meio - MG, verificando as dificuldades e potencialidades do cultivo do café agroecológico na região que detêm $25 \%$ da produção de café no Brasil. Os resultados são oriundos de dois projetos - extensão e pesquisa - e pode-se constatar a dificuldade encontrada pelos agricultores familiares referentes aos aspectos econômicos, dependência à produção convencional, e carência de assistência técnica dado pela falta de técnicos especializados para fazer a transição agroecológicas nas propriedades familiares. Existem cooperativas na região que promovem a produção agroecológica do café, mas em pequena escala, tendo grandes dificuldades para captar agricultores nesse processo, devido, sobretudo, ao tempo da transição para sistemas mais sustentáveis e da dependência econômica aos métodos convencionais.

Palavras-chave: : Agroecologia, agricultura familiar, desenvolvimento, região.
\end{abstract}

\section{Introdução}

Segundo dados do censo agropecuário do ano de 2000 existem 4.139.369 estabelecimentos familiares no Brasil, ou seja, $85,2 \%$ do número total de estabelecimentos agropecuários do país, este segmento rural ocupa uma área de 107.768 mil hectares, o que corresponde a $30,5 \%$ do território destinado a agricultura. A agricultura familiar é responsável por $37,9 \%$ do valor bruto da produção gerada no Brasil (SOUZA, 2006). A diversificação produtiva é a principal característica da agricultura familiar sendo que no Brasil os "agricultores familiares são responsáveis pela produção de 81,4 $\%$ do feijão, assim como $72 \%$ dominam a produção de leite, e 97,7 \% estão envolvidos com aproximadamente $36,4 \%$ da produção de milho. " - (VALENTE, 2008, p.13).

Assim, estudar a agricultura familiar nas diferentes escalas de análise (nacional, regional e local ou meso, micro e local) pode contrastar a realidade geográfica numa interpretação regional servindo de base para planejamentos e diagnósticos socioeconômicos. Nesse sentido, a pesquisa consiste em interpretações em escalas geográficas variadas, no primeiro momento uma caracterização da mesorregião Sul/Sudoeste de Minas, em seguida uma verificação da microrregião de Alfenas e, por fim, uma análise local do município de
Alfenas.

Na mesorregião Sul/Sudoeste de Minas Gerais vivem 2.346.077 habitantes espalhados em seus 146 municípios, com cerca de 530 mil delas habitando em meio rural (IBGE, 2010). Essa região tem como cultura agrícola principal o café, englobando agricultores familiares e grandes produtores. A cafeicultura familiar no Sul de Minas Gerais atenta para importância da pequena propriedade na região que conta com 5 mil estabelecimentos agrícolas familiares "apresentando uma diversidade de técnicas de produção e a multiplicação dos processos inovadores de comercialização, notadamente o comércio justo e orgânico". (SILVEIRA, MARQUES, 2009, p.233).

$\mathrm{Na}$ microrregião de Alfenas - $\mathrm{MG}^{4}$ (Figura 1), a cafeicultura está presente em $53,78 \%$ dos estabelecimentos agropecuários e ocupa 55,81\% da área total conforme o Sistema IBGE de Recuperação Automática (SIDRA, 2006), evidenciando a especialização produtiva e a importância econômica da atividade para a região. Os dados do ano de 2006, até então os últimos divulgados pelo SIDRA, mostram que cerca de $80 \%$ dos estabelecimentos agropecuários da microrregião enfatizada são de agricultores familiares. Entretanto, esses estabelecimentos ocupam pouco mais de $37 \%$ da área total, deixando clara a forte concentração de terras presente na região.

${ }^{4}$ Formada por doze municípios Alfenas, Alterosa, Areado, Carmo do Rio Claro, Carvalhópolis, Conceição da Aparecida, Divisa Nova, Fama, Machado, Paraguaçu, Poço Fundo, Serrania. 


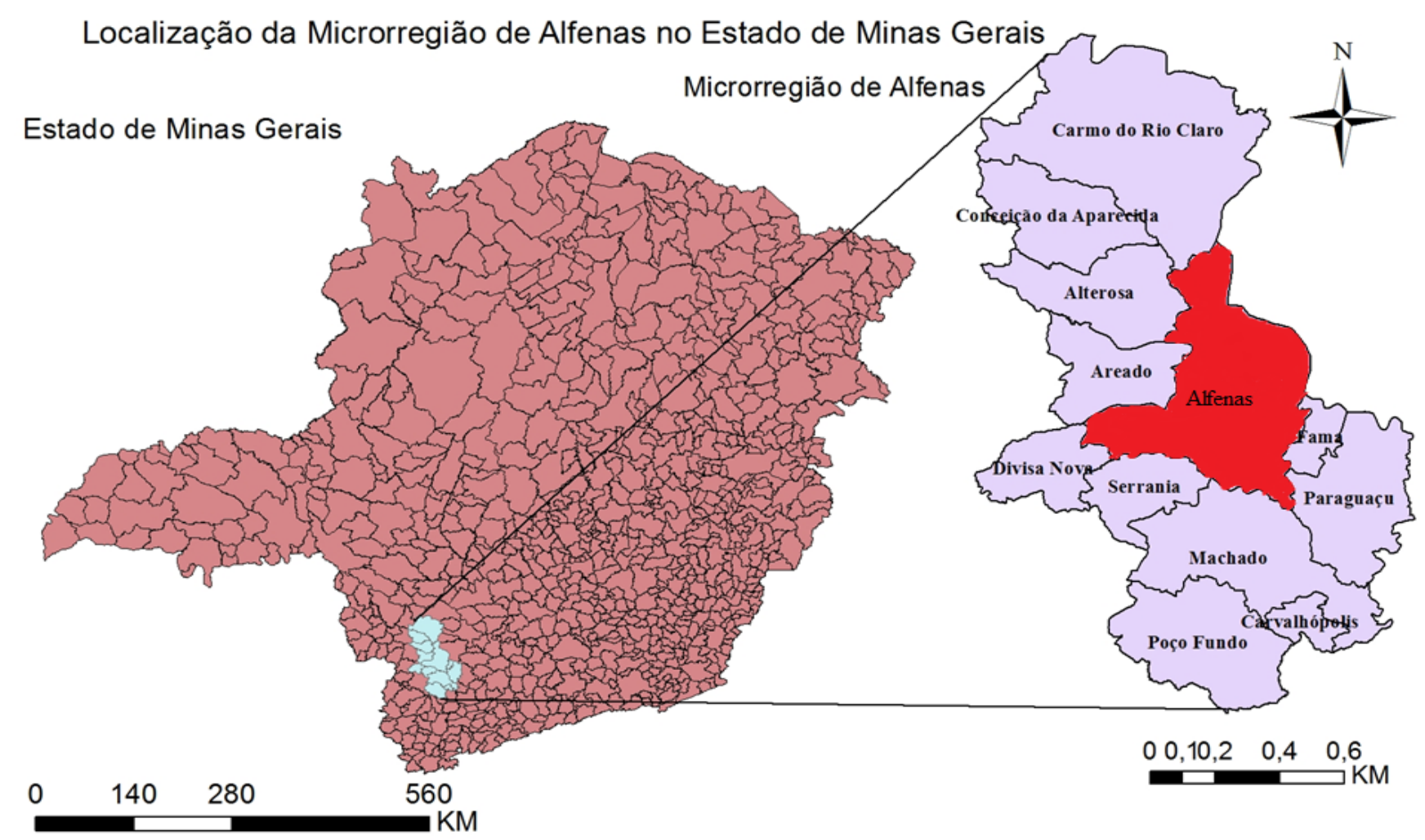

\footnotetext{
Elaboração: Mayara Fontes Dantas

Data: novembro de 2011

Fonte: IBGE - Base Cartográfica Digital
}

Fonte: IBGE - Base Cartográfica Digital - Elaboração: Mayara Fontes Dantas

O município de Alfenas conta com 73.722 mil habitantes (IBGE 2010). Segundo dados do censo agropecuário de 2006, o município de Alfenas apresenta 786 unidades de estabelecimentos agrícolas familiares que representa $71,5 \%$ do total de estabelecimentos agrícolas do município, já a área ocupada pela agricultura familiar no município é de 11.908 ha, ou seja, 21,70\% do total da área ocupada pela prática agrícola no município.

A atividade cafeeira como uma das principais atividades econômicas do sul de Minas Gerais atua de forma significativa na organização do espaço rural e urbano da região, sendo de fundamental importância abordar a organização dessa atividade nas unidades familiares em suas várias escalas. 0 cultivo do café apresenta-se, na maioria das vezes, na forma tradicional de cultivo, ou seja, com uso intensivo de fertilizantes artificiais e defensivos agrícolas, tendo poucas iniciativas com práticas agroecológicas.

O objetivo do trabalho é identificar como alguns aspectos referentes à agroecologia e a agricultura familiar estão presentes no mercado de produção agrícola no sul de Minas Gerais - ressaltando a importância da cafeicultura das pequenas propriedades. Tem como estudo de caso a feira livre do município de Alfenas e a experiência acerca da realidade da produção agrícola do assentamento Primeiro do Sul do município de Campo do Meio - MG. A idéia geral do trabalho consiste em considerar essas duas realidades - a feira de livre de Alfenas e o assentamento do Campo do Meio - MG como vetores de desenvolvimento regional dentro das perspectivas da ciência agroecológica.

\section{Metodologia}

A pesquisa resulta de dois projetos realizados pelo grupo de estudos GERES - Grupo Estudos Regionais e Socioespaciais - da Universidade Federal de Alfenas MG no período entre agosto de 2011 a abril de 2012. Um projeto de extensão acerca da produção agroecológica e convencional no assentamento Primeiro do Sul no município de Campo do Meio - MG e um projeto de iniciação científica sobre aspectos teóricos da agroecologia e da agricultura familiar tendo como referência a feira de produtores no município de Alfenas - MG.

Procurou-se estudar as diferentes realidades presentes na pesquisa sob a ótica de diferentes escalas, além de analisar as condições dos assentamentos rurais frente o ideal agroecológico. No caso da feira ${ }^{5}$ ela foi selecionada pelo fato de reunir agricultores de Al-

${ }^{5} \mathrm{~A}$ feira acontece semanalmente aos domingos no centro da cidade de Alfenas - MG. 
fenas e outros municípios da micro e mesorregião em estudo.

Para execução dessa pesquisa foram realizados levantamentos bibliográficos sobre alguns conceitos e teorias sobre a agroecologia, sustentabilidade e agricultura. Além do levantamento bibliográfico, foram feitas buscas por dados estatísticos no site do IBGE. Por fim, foram realizados um trabalho de campo na feira livre de Alfenas-MG e outro no assentamento Primeiro do Sul em Campo do Meio - MG. O trabalho de campo na feira livre teve como objetivo entender com mais especificidade o caráter produtivo que sustenta o funcionamento da feira, para isso foi feito um questionário com diversas perguntas relacionadas ao modo como é produzido, quem produz, onde é produzido e qual a relação dos produtores da feira com a prática da agricultura familiar. Já no que se refere ao trabalho de campo feito no assentamento, foi aplicado um questionário avaliando as dificuldades e as potencialidades para a implantação de um sistema agroecológico de produção na referida área.

\section{Discussões teóricas da agricultura na Geogra- fia}

Em uma tentativa de encontrar uma definição sobre o conceito de agricultura Diniz (1984), aponta a agricultura como sendo uma prática dispersa e diversificada na superfície terrestre, sua dispersão se dá basicamente pelos diferentes meios ecológicos nos quais são registradas as práticas da agricultura, no entanto, a agricultura torna-se diversificada ao atender diferentes necessidades sociais, econômicas e políticas. Nesse sentido, o autor assume a existência de diversos estágios da prática agrícola, ou seja, em alguns lugares e devidos a alguns fatores a prática da agricultura pode ser considerada mais moderna e em outros lugares mais rudimentares, no geral, esses fatores referem-se ao grau técnico e científico que permeia determinada prática agrícola.

Ainda segundo, Diniz (1984), a agricultura não se restringe apenas a produção vegetal, mas também pode ser uma produção que envolve a criação de animais. Por fim, o autor atenta para importância da agricultura, visto que a prática é fundamental para garantir a subsistência de uma população, e ou impulsionar a economia de uma nação quando aliada a produção industrial por exemplo. Pode-se observar que a agricultura por envolver uma gama de aspectos que ultrapassam a concepções meramente ecológicas, necessita de um estudo que consiga estabelecer inter-relações entre as condições nas quais são praticadas a agricultura, condições sejam elas sociais, econômicas e políticas.

Na geografia a agricultura como objeto de estudo encontra-se no cerne de algumas vertentes da disciplina. Andrade (2010) separa essas vertentes entre geografia agrária, geografia agrícola e geografia rural. Segundo o referido autor (2010) aponta que a geogra- fia agrária estaria ligada a problemática da estrutura fundiária e as relações de trabalho no meio rural, enquanto a geografia agrícola aborda problemas relacionados à produtividade e rentabilidade da produção no campo, tendo esses estudos maior ênfase econômica. Para o mesmo autor tanto a geografia agrária quanto a geografia agrícola tornaram-se insuficiente para explicar a evolução das relações socioeconômicas ocorridas no campo ao longo do século XX, desse modo a geografia rural surge com a proposta de compreender a complexidade dessas relações que agora não mais estavam ligadas somente a agricultura, mas também a atividades de caráter mais urbano. Nesse sentindo, Andrade (2010) afirma:

A partir daí, se pode inferir que a Geografia Rural, sem abrir mão de suas preocupações com a economia agrícola e agrária, dava uma ênfase especial à paisagem chamando atenção para atividades econômicas mais diversificadas, como o comércio, a indústria, os transportes e o turismo, efetivadas no campo. Daí admitir-se, pelo menos como hipótese de trabalho, que a denominação de Geografia Rural traz um compromisso maior com a totalidade e com o conhecimento mais aprofundado da paisagem, valorizando um conceito que vinha caindo em desuso. (ANDRADE, 2010, p. 10 e 11)

Para Andrade (2010) o entendimento das questões teórico-metodológicas relacionadas às definições sobre geografia agrária, geografia agrícola e, sobretudo a geografia rural é de suma importância para o geógrafo, visto que na condição de cientista social o mesmo tem por objetivo entender as complexidades e o constante movimento que envolve a temática. 0 autor propõe a análise das particularidades contidas em cada objeto de análise de modo que "a observação e a preocupação com a diversificação devem permanecer no raciocínio do estudioso" (ANDRADE, 2010, p. 16) contrapondo o rigor dos modelos generalistas.

Logo a abordagem agroecológica e da agricultura sustentável estaria ligada as diferentes abordagens referidas - geografia da agricultura, geografia rural e geografia agrária - já que trata das alterações nas estruturas das produções agrícolas, mudando relações econômicas, sociais e ambientais como veremos nos tópicos a seguir

\section{Agricultura familiar e "agribussines": diferencia- ção dos termos}

0 termo agricultura familiar nasceu com a proposta de distinção entre o referido tipo de produção e os setores rurais que remetiam a ineficiência produtiva como "pequena produção" e "produção de subsistência". No Brasil o termo foi cunhando sob um contexto de fortalecimento e mobilização política por parte dos 
sindicatos rurais que acabou culminando na criação do mais importante programa voltado para agricultura familiar o Programa Nacional de Fortalecimento da Agricultura Familiar (PRONAF) em meados de 1995. No lado oposto, o termo "agribussines" ou agronegócio se baseia na premissa da existência de uma cadeia de produção integrada que envolve diversas etapas, desde a produção propriamente dita no campo até o processo de transformação industrial do produto. 0 termo foi definido com o intuito de integrar e diferenciar um segmento produtivo estritamente ligado aos processos de modernização agropecuária no Brasil e como um setor completamente integrado ao mercado globalizado (SAUER, 2008).

Os anos de 1990 foi um período importante para estabelecimento das diferenciações conceituais acerca da agricultura familiar e agronegócio, sobretudo por ter sido um período de grandes transformações políticas tanto no âmbito da regulação dos processos produtivos relacionados à agricultura - culminando no fortalecimento de associações de classes e entidades organizadas não ligadas diretamente ao governo - como pelo estabelecimento definitivo da lógica da Revolução Verde como principal indutor da produção agrícola no Brasil. Assim como assinala Sauer (2008):

No mesmo período (início dos anos 1990), a dinâmica sociopolítica do meio rural brasileiro - historicamente marcada por disputas entre grandes proprietários (setor patronal e suas entidades de representação) e setores marginalizados - estabeleceu uma oposição entre os conceitos de agronegócio e de agricultura familiar. Esse contexto e as estratégias de legitimação resultaram no uso corrente e dominante do termo agronegócio como um processo de modernização tecnológica excludente e de apropriação e/ ou concentração da terra e da renda, associando o conceito ao modelo agropecuário dominante adotado com a implantação da Revolução Verde. Esse termo expressa, consequentemente, um antagonismo político e simbólico à agricultura familiar ou camponesa, considerando-a uma forma arcaica e pouco eficiente de produção e cultivo da terra, especialmente pela não incorporação de certa racionalidade técnica. (SAUER 2008. p. 30)

Portanto, esses dois tipos de produção agrícola não somente apresentam diferentes conceituações teóricas, mas são também práticas socioeconômicas diferentes entre si e antagônicas, de modo que a agricultura familiar se opõe essencialmente ao modelo convencional de produção agrícola enquanto o "agribussiness" estaria intimamente ligado ao modelo de produção agrícola estabelecido com a Revolução Verde.

\subsection{Agricultura sustentável e agroecologia}

No Brasil o tema da sustentabilidade ganhou força após a década de 1980 juntamente com a crise econômica, e a consequente desregulamentação dos mercados agrícolas por parte do Estado. Segundo Hespanhol (2002) a adoção de inovações técnicas na agropecuária provocou o aumento da dependência desse segmento produtivo a fontes externas de energia, principalmente o petróleo - a dependência de fontes externas de energia e a produção de um reduzido número de espécies vegetais e animais em larga escala provocou significativas alterações nos ecossistemas naturais.

Segundo Hespanhol (2001) na agricultura sustentável, em geral, o cultivo é realizado em pequenas áreas, nas quais são produzidos diversos vegetais, fazendo, sempre que possível a integração com a produção animal para o aproveitamento do adubo orgânico. Os conhecimentos do produtor ("saber fazer") e sua cultura são valorizados. Procura-se atingir um melhor equilíbrio energético: não se recorre a fontes externas de energia ou as mesmas são utilizadas o mínimo possível. Nesse sentido, afirma-se o caráter sistêmico da agricultura sustentável, pois envolve tanto os aspectos físicos e naturais da produção quanto aspectos culturais locais e econômicos.

Dentro desse contexto de práticas de agricultura sustentáveis podemos identificar a agroecologia como uma ciência com um enfoque teórico e metodológico caracterizado pela multidisciplinaridade onde é central o conceito de transição agroecológica. Para Caporal e Costabeber (2004):

[...] o conceito de transição agroecológica, entendida como um processo gradual e multilinear de mudança, que ocorre através do tempo, nas formas de manejo dos agroecossistemas, que, na agricultura, tem como meta a passagem de um modelo agroquímico de produção (que pode ser mais ou menos intensivo no uso de inputs industriais) a estilos de agriculturas que incorporem princípios e tecnologias de base ecológica. Essa idéia de mudança se refere a um processo de evolução contínua e crescente no tempo, porém sem ter um momento final determinado. (CAPORAL \& COSTABEBER 2004, p. 12)

A agroecologia dentro dessa perspectiva não descarta o progresso técnico e o avanço do conhecimento científico, porém apresenta novas formas de apropriação das técnicas e conhecimentos científicos já existentes, assim como propõe a criação de novas técnicas e a construção de um conhecimento equilibrado tanto no que diz respeito aos aspectos ambientais quanto sociais e econômicos. Para Caporal e Costabeber (2004) é necessário que se diferencie a agroecologia de atividades agrícolas que usam alguns aspectos sustentáveis na produção com o intuito de buscar nichos de mercados específicos e que se restringem a uma parcela restrita 
de produtores.

\subsection{Agroecologia e agroecossistemas}

É de fundamental importância entender que a agroecologia parte do reconhecimento dos aspectos ecológicos e sociais locais e regionais para fundamentar suas ações, ou seja, o saber-fazer local, os aspectos culturais, a tradição assim como o ecossistema de uma região são fatores que devem ser compreendidos para apropriação dos recursos. Ao contrário do método convencional agrícola atualmente praticado, a agroecologia orienta-se a partir do âmbito local e não tem por objetivo o êxito meramente econômico, mas busca o equilíbrio entre os processos de apropriação induzidos pelo homem e o processo natural de regeneração e funcionamento dos organismos naturais.

Desse modo, a pesquisa agroecológica além de envolver diversas disciplinas e campos do conhecimento, propõe um enfoque sistêmico aos estudos, dentro disso o conceito metodológico de agroecossistemas aparece com fundamental para os estudos agroecológicos. Partindo dessa idéia os autores Caporal e Costabeber baseando-se em Altieri (1989) afirmam:

Agroecossistema é a unidade fundamenta de estudo, nos quais os ciclos minerais, as transformações energéticas, os processos biológicos e as relações sócio-econômicas são vistas e analisadas em seu conjunto. Sob o ponto de vista da pesquisa agroecológica, seus objetivos não são a maximização da produção de uma atividade particular, mas a otimização do agroecossistema como um todo, o que significa a necessidade de uma maior ênfase no conhecimento, na análise e na interpretação das complexas relações existentes entre as pessoas, os cultivos, o solo, a água e os animais. (CAPORAL E COSTABEBER, 2004 apud ALTIERI, 1989 p. 11)

A agroecologia vai além da simples substituição de recursos não renováveis por recursos naturais e renováveis na prática agrícola, mas dá importância também aos processos químicos que envolvem a prática, nesse sentido, os autores Caporal e Costabeber (2004) afirmam que "é preciso ter presente que a simples substituição de agroquímicos por adubos orgânicos mal manejados pode não ser solução, podendo inclusive causar outro tipo de contaminação" (CAPORAL E COSTABEBER, 2004, p. 10).

Para a construção e o fortalecimento da pesquisa e da prática agroecológica é necessário que haja uma junção de diversos conhecimentos e a busca de métodos que entendam o funcionamento dos ecossistemas de forma holística. Entender a agroecologia como um processo de transição entre um sistema de prática agrícola predatório para um sistema sustentável é também um processo de estabelecimento de novos valores nas ações do homem, assim como assinala Caporal e Costabeber 2004:

[...] por se tratar de um processo social, isto é, por depender da intervenção humana, a transição agroecológica implica não somente na busca de uma maior racionalização econômico-produtiva, com base nas especificidades biofísicas de cada agroecossistema, mas também numa mudança nas atitudes e valores dos atores sociais em relação ao manejo e conservaçãodos recursos naturais. (CAPORAL E COSTABEBER, 2004, p. 12)

O debate da agroecologia e a agricultura familiar estão intimamente relacionados já que partem, em essência, da contraposição ao modelo de produção agrícola estabelecido pela Revolução Verde. Além de que, de modo geral, a agricultura familiar oferece um substrato social mais condizente com as demandas da agricultura sustentável e agroecológica. No entanto, como exposto acima trata-se de um processo complexo já que depende da integração de diversas áreas do conhecimento científico e "popular", além de iniciativas governamentais que oferecem base para reconversão produtiva nas mais diferentes escalas.

\section{A realidade do campo e agricultura no sul de Mi- nas Gerais}

O Brasil por apresentar uma grande diversidade territorial e sociocultural necessita de estudos que apontem as limitações e avanços da prática da agricultura sustentável e agroecológica em suas diferentes realidades. 0 objetivo desse tópico é o de acrescentar novas perspectivas teóricas e práticas à temática a partir de dois estudos de casos realizados no Sul de Minas Gerais.

\subsection{Feira livre de Alfenas}

Sempre ao domingo é realizada a Feira Livre, composta por 516 feirantes cadastrados na Secretaria de Desenvolvimento Rural de Alfenas, destes 219 pertencem à cidade de Alfenas, e os demais são de vários municípios da micro e mesorregião do Sul de Minas, chegando a 57,6 \% do total dos feirantes. Do total, 128 cadastros são de atravessadores, pessoas que compram direto do produtor ou em CEASAS e revendem na feira (CODIGNOLE, 2011).

$\mathrm{Na}$ pesquisa realizada na feira livre do município de Alfenas - MG (Foto 1), foram entrevistados 64 agricultores de vários municípios da microrregião de Alfenas - MG sendo que 42 deles não cultivam café e, normalmente, têm como principal fonte de renda a comercialização dos alimentos na feira. A área média das propriedades desses agricultores gira em torno de 5,5 ha. Para os agricultores que plantam café a situação é 
um pouco diferente porque para a maioria a principal fonte de renda vem da produção cafeeira e a área média de suas propriedades é de aproximadamente 22,3 ha.

Figura 2 - Feira livre do município de Alfenas - MG realizada aos domingos

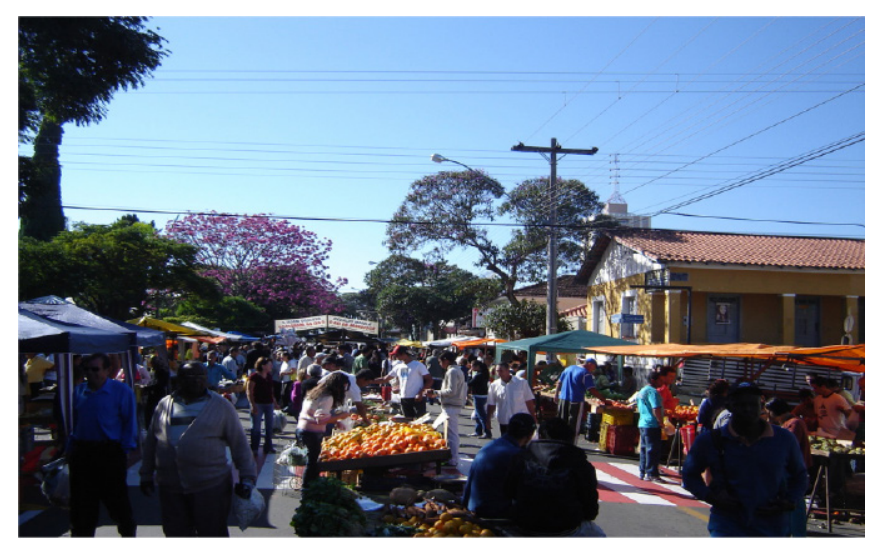

Fonte: Artur Leonardo Andrade

Para muitos produtores, além da comercialização dos alimentos na feira são necessárias outras atividades para complementar a renda familiar, como a transformação dos alimentos em doces, a pesca, pecuária, a revenda de outros alimentos conseguidos em empresas da região, a comercialização de roupas, entre outras.

Foi possível perceber que a agricultura familiar é responsável por grande parte da produção de gêneros alimentícios básicos para população da microrregião de Alfenas - MG. Entretanto, essa produção é consequência de uma desigualdade social, pois quem tem melhores condições econômicas e técnicas, optam pelo cultivo convencional do café (atividade mais lucrativa), pensando cada vez menos na diversidade produtiva e nas práticas sustentáveis. Por outro lado, a feira apresenta uma complexidade de formas de comercialização e organização, e não se restringe a produção tradicionalmente familiar, ou seja, na feira coexistem formas de organização que vai além da existência produtor familiar que comercializa o produto agrícola na feira. Foi possível identificar a intermediação de empresas produtoras agrícolas que vendem os produtos para terceiros, esses revendem os produtos na feira e não tem nenhuma relação direta no processo de cultivo e produção agrícola, servem apenas como comerciantes que procuram uma renda alternativa e não têm nenhum vínculo com a prática da agricultura ou sequer possuem propriedade de terra.

No caso, deste trabalho da feira livre de Alfenas, encontram-se muitos comerciantes que mantêm vínculos com esse tipo de empresas intermediárias. A Minas Frutas é a principal empresa que atua nesse sentindo na feira livre de Alfenas. A referida empresa possui uma propriedade de 300 hectares no município de Santo Antônio do Amparo-MG que é divida em 4 lotes e produzem basicamente café e citros (laranja, limão, mexerica/bergamota), sendo que 100 ha da propriedade é destinado a produção de café e o restante para a produção de citros. Santo Antonio do Amparo fica a uma distância de $159 \mathrm{~km}$ de Alfenas, ligados pela rodovia federal Fernão Dias. A empresa é responsável pela venda de produtos agrícolas, notadamente a laranja, para diversos municípios de Minas Gerais. Em Alfenas, a empresa possui uma sede que além do serviço de venda faz também o beneficiamento do produto. Além da feira livre, a empresa vende para empresas de sucos do Estado de São Paulo e supermercados do município de Alfenas e região, porém os clientes advindos da feira livre de Alfenas não mantêm um vínculo constante com a empresa, pois a demanda oriunda da feira oscila de acordo com a variação de preços dos produtos vendidos pela empresa.

Nesse sentido, a feira livre é uma forma de manutenção econômica para a população do campo e da cidade, sendo um agente de desenvolvimento regional incorporando pequenos, médios e grandes agricultores numa cadeia produtiva complexa, interligando campo-cidade e produção tradicional e agroecológica.

\subsection{Assentamento Primeiro do Sul - Campo do Meio - MG}

A questão fundiária no sul de Minas é bastante distinta e apresenta atualmente três assentamentos rurais na região $0^{6}$. Estes assentamentos rurais para manter sua reprodução socioeconômica tratam de associar práticas tradicionais de plantio com práticas agroecológicas, como meio de inserção no mercado e subsistência.

Durante trabalhos realizados no assentamento Primeiro do Sul, localizado no município de Campo do Meio - MG foi possível analisar alguns elementos relevantes para as práticas agroecológicas, como a significativa preservação dos recursos naturais, consistente consciência política dos agricultores, que criticam a pouca atenção dada pelas políticas públicas de assistência do Governo Federal e Estadual aos agricultores, além de ressaltarem a importância do trabalho coletivo no lugar, porém há somente cooperação durante a colheita do café.

No assentamento existem 48 famílias residentes em propriedades onde há produção convencional do café, produção de café orgânico e, também, uma propriedade com produção mista, ou seja, que busca a transição do cultivo tradicional para o orgânico. Cada família tem em média 14 hectares para a produção de café e em 2012 - 2013, a produção do assentamento foi de aproximadamente 2500 sacas de $60 \mathrm{~kg}$. A produção, tanto orgânica quanto convencional, é vendida para Cooperativa de Cafeicultores de Campos Gerais e Campo do Meio (COOPERCAM). Em 2013, o processo de transição para o café agroecológico foi atingido, apesar das dificuldades de livrar-se dos agrotóxicos, e das dificuldades para deixar sua produção ambientalmente

${ }^{6}$ Três assentamentos rurais, no município de Guapé, e dois em Campo do Meio 
sustentável porque não tem recursos suficientes para produção de insumos e assistência técnica adequada, a questão principal é a viabilidade econômica, comercial e técnica.

Figura 3 - Café agroecológico produzido na Assentamento Primeiro do Sul - Campo do MeioMG.

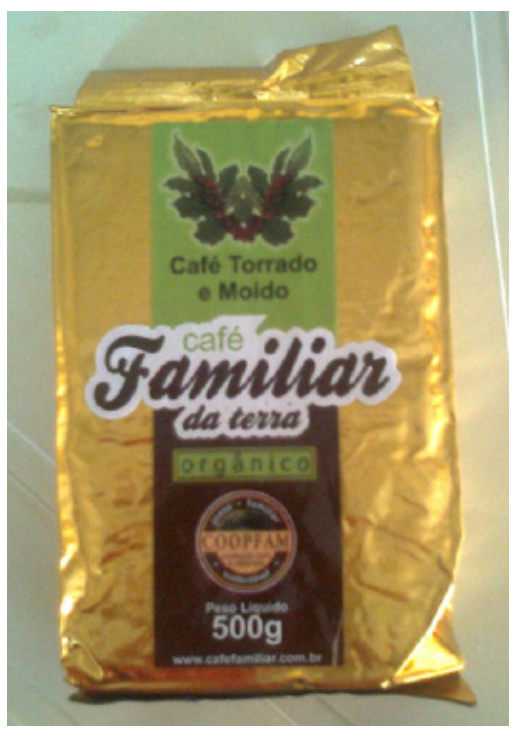

Fonte: http://www.mst.org.br/sites/default/files/cafe.jpg

A dificuldade para esse tipo de produção agroecológica, é que trata-se de uma técnica de médio a longo prazo até a limpeza total do solo e ambiente. Como a região é ocupada pela monocultura do café tradicional e as dezenas de cooperativas de café existentes na região dão suporte e marcam presença nas unidades familiares, dificulta a transição das práticas convencionais para as agroecológicas.

Todos os produtores familiares entrevistados não estão de acordo com o custo de produção do café convencional, pois os preços dos insumos são extremamente elevados, incompatíveis com a agricultura familiar local. Mesmo assim, durante a apresentação das propostas, poucos produtores estavam dispostos a diversificar suas produções para o mercado, o que é totalmente compreensível e deve ser sempre considerado, pois eles estão inseridos em uma região estruturada para a produção do café, produto bastante lucrativo, se considerar que a agricultura familiar brasileira é historicamente impedida de desenvolver suas potencialidades. A policultura no assentamento rural é composta por feijão, mandioca, criação de gado, aves, milho, banana, hortaliças entre outros, basicamente para subsistência das famílias, e o café sendo a cultura direcionada ao mercado.

\subsection{Café no Sul de Minas: da commodity ao café orgânico e especial}

O Brasil é o país que mais exporta café, sendo responsável por $30 \%$ da produção mundial, cerca de $30 \%$ milhões de 60kg anuais (safra 2007/2008) (Ver. Tabela 1). Grande parte do café produzido é voltado para exportação. Minas Gerais é o principal estado produtor do país, produzindo cerca de $50 \%$ do montante da produção nacional (ANUÁRIO ESTATÍSTICO DO CAFÉ, 2008). 0 estado de Minas Gerais possui diversas regiões especializadas na cultura do café, a mesorregião do Sul/Sudoeste, pode ser citada como a principal região produtora totalizando $25 \%$ da produção nacional (IBGE, 2008).

Além do elevado nível de produção da região, caracterizado pela produção de commodities, a região também apresenta tipos de organizações diversas e que procuram valorizar aspectos diferenciados na produção de café, podemos citar como exemplo a COOPFAM - Cooperativa de Agricultores Familiares de Poço Fundo-MG. A COOPFAM foi pioneira no sentindo de produzir cafés orgânicos na região, inicio as atividades em 1991 com o intuito de valorizar a produção familiar, orgânica e o comércio justo do café. Outra iniciativa importante na região no sentido de valorizar a pequena

Tabela 1 - Produção e Exportação Mundial de Café (2011) - Volume em mil sacas de $60 \mathrm{~kg}$

\begin{tabular}{|c|c|c|c|c|}
\hline Países & Produção & Particip. (\%) & Exportação & Particip. (\%) \\
\hline Brasil & 43.154 & 33,57 & 33.610 & 33,82 \\
\hline Vietnã & 18.500 & 14,39 & 14.229 & 13,90 \\
\hline Colômbia & 8.500 & 6,61 & 7.822 & 7,64 \\
\hline Indonésia & 8.750 & 6,81 & 5.489 & 4,36 \\
\hline Etiópia & 6.350 & 4,94 & 4.395 & 3,73 \\
\hline Índia & 5.500 & 4,28 & 3.817 & 3,39 \\
\hline Honduras & 4.300 & 3,34 & 3.468 & 3,27 \\
\hline México & 4.500 & 3,50 & 3.349 & 3,25 \\
\hline Peru & 4.447 & 3,46 & 3.324 & 1,44 \\
\hline Guatemala & 3.600 & 2,80 & 2.498 & 1,67 \\
\hline Costa do & 1.600 & 1,24 & 1.916 & 1,06 \\
\hline Marfium & & & & 15,32 \\
\hline EISalvador & 1.450 & 1,13 & 1.712 & 100,00 \\
\hline Nicarágua & 1.800 & 1,40 & 1.082 & 15.689 \\
\hline Outros & 16.109 & 12,53 & 102.400 & \\
\hline Total & 128.560 & 100,00 & 120 & \\
\hline
\end{tabular}

Fonte: ABIC (2012) 
produção e os aspectos ambientais e sociais da produção é a da APROCAM - Associação dos Produtores de Café da Mantiqueira. A associação início as atividades em 1996 com o intuito de valorizar o café produzido na região valorizando aspectos territoriais e sociais. Foi a primeira Associação a conseguir o selo de Indicação de Procedência do café na mesorregião Sul/Sudoeste, esse selo tem por objetivo garantir a exclusividade do café, associando qualidade ao local de produção, com isso é possível agregar um maior valor produto.

Como se pode observar na mesorregião Sul/Sudoeste de Minas convivem diversos tipos de organização e produção associadas ao café, devido principalmente, a tradição na região do cultivo cafeeiro. Contudo, diversos aspectos infraestruturais e políticos amparam esse tipo de produção na região. A região possui diversos armazéns especializados no armazenamento e beneficiamento do café, além de possuir um porto seco no município de Varginha com objetivo de facilitar o escoamento da produção para o Porto de Santos. No que se refere à política observa-se uma forte atuação da EMATER-MG que só no município de Alfenas atua junto a 490 produtores de café, além das diversas cooperativas e associações voltadas para a conformação da produção cafeeira, entretanto, essa assistência técnica segue o modelo convencional de produção.

\section{Conclusões}

Com a realização desse trabalho foi possível fazer um levantamento de algumas questões relevantes para a discussão, compreensão e para o desenvolvimento da realidade da agricultura familiar e da agroecologia no Sul/sudoeste de Minas Gerais:

- Maior facilidade da implantação de um sistema agroecológico em casos como o do assentamento de Campo de Meio. Os produtores apesar dos empecilhos técnicos e financeiros apresentam uma boa consciência ecológica, social e política no que diz respeito à produção agrícola, além de que, possuem formas de organização da propriedade mais compatíveis com os conceitos agroecológicos. No caso da implantação de um sistema agroecológico o assentamento pode ser um bom lugar para essa experiência.

- Pouco conhecimento dos produtores familiares e das empresas agrícolas acerca dos conceitos agroecológicos. A dependência do mercado agrícola ao mercado financeiro global que estabelece os preços e a falta de aparato técnico-científico, não possibilita margens para uma reconversão produtiva agroecológica, uma tentativa nesse sentido, levaria tempo e muito dinheiro e o Estado não oferece bases suficientes para sustentar os produtores para esses tipos de reconversão produtiva. Além do fato de que são necessários esforços maiores para construir bases técnicas e levar a informação ao produtor a respeito da produção agroecológica.

- Complexidade de formas de organização dentro da feira: produtores familiares e comerciantes inter- mediados por empresas agrícolas coexistem no mesmo espaço. No caso das empresas agrícolas, pode-se dizer que essa atividade resulta, sobretudo, de iniciativas de produtores que buscam maiores parcelas do mercado e que, por isso se organizam de formas diferenciadas com intuito de integrar-se ao mercado de forma mais competitiva. Por outro lado, tanto a prática familiar da agricultura quanto a atuação de empresas agrícolas, são iniciativas isoladas e não capazes de integrar os produtores da região com o intuito de valorizar e melhor comercializar os produtos agrícolas.

- Uma grande dependência ao cultivo do café, devido, principalmente, à tradição regional no cultivo desse produto. Nesse sentido podem-se avaliar duas questões:

a) para a parcela restrita de produtores de commodities o café ainda é uma forma lucrativa de produção, porém os altos custos para manter e iniciar esse tipo de produção aparecem como empecilhos para produtores que pretendem ingressar nesse segmento. Os pequenos produtores que ainda produzem da forma convencional apesar da insatisfação diante preço do café convencional no mercado, não optam por diversificar a produção devido, principalmente, a estruturação regional voltada para a produção do café;

b) para a também restrita parcela de produtores organizados em torno de produções de cafés orgânicos e especiais, o café também é uma atividade capaz de produzir uma boa renda, por outro lado esses tipos de produções apesar de apresentarem formas de produzir mais compatíveis com a pequena produção e a agricultura familiar, ainda carecem de desenvolvimento na região. Pode-se afirmar isso, diante um relativo alto custo para iniciar-se nesse segmento produtivo, além da questão técnica aparecer também como um grande entrave, visto que esse tipo de produção exige processo produtivo bastante diferenciado e um conhecimento científico específico. Com isso, essas iniciativas aparecem de forma dispersa e não abarcam um a parcela significativa da realidade da produção cafeeira na mesorregião Sul/Sudoeste de Minas Gerais.

\section{Referências Bibliográficas}

ALTIERI, M. A. Agroecologia: as bases científicas da agricultura alternativa. Rio de Janeiro: PTA/FASE, 1989.

ANDRADE, Manuel C. de. Geografia Rural; questões teórico-metodológicas e técnicas. p. 3 -14. In: CAMPO-TERRITÓRIO: revista de geografia agrária, v. 5, n. 9, p. 5-16, fev. 2010.

CAPORAL, R. C; COSTABEBER, J. A. Agroecologia e sustentabilidade. Base conceitual para uma nova extensão rural. In: X Word Congressof Rural Sociology, 2000. Rio de Janeiro. 27 p.

CAPORAL, R. C; COSTABEBER, J. A. Agroecologia: conceitos e princípios. Brasília: MDA/SAF/DATER-IICA, 2004. 
$24 \mathrm{p}$.

CODIGNOLI, R.C. Importância econômica da agricultura familiar no município de Alfenas/MG: o caso das feiras livres. Trabalho de Conclusão de Curso (Geografia). Universidade Federal de Alfenas, 2011.

COFFEE BUSINESS. Anuário Estatístico do Café 2008. Anuário Estatístico do Café, 2008.

DANTAS, M.F. Impactos da modernização da agricultura na estrutura agrária sul mineira na microrregião de Alfenas - MG. Trabalho de Conclusão de Curso - Universidade Federal de Alfenas, Alfenas, 2011.

DINIZ, J. A. F. Geografia da Agricultura. São Paulo: DIFEL, 1984. 277 p.

HESPANHOL, A. N. Agricultura, desenvolvimento e sustentabilidade. In: MARAFON, G.J. et AL. (orgs). Abordagens teóricos-metodológicas em geografia agrária. Rio de Janeiro: Editora da UERJ, 2007.

INSTITUTO BRASILEIRO DE GEOGRAFIA E ESTATÍSTICA - Banco de dados agregados: Disponível em: <www. ibge.gov.br> Acesso em: 17 abr. 2012.
INSTITUTO BRASILEIRO DE GEOGRAFIA E ESTATÍSTICA. Banco de dados agregados: sistema de recuperação automática - SIDRA. Brasília, 2009. Disponível em: <http:// www.sidra.ibge.gov.br>. Acesso em: 17 abr. 2012.

SAUER, S. Agricultura familiar versus agronegócio: a dinâmica sociopolítica do campo brasileiro. Brasília: Embrapa Informação Tecnológica, 2008.

SILVEIRA, M. A; MARQUES. P. E. M. Desenvolvimento Territorial e Multifuncionalidade da cafeicultura familiar no Sul de Minas Gerais. IN: CAZELLA, A. A. et AL. (orgs). Agricultura Familiar Multifuncionalidade e desenvolvimento territorial no Brasil. Rio de Janeiro: Mauad X, 2009. P. 229 a 250.

SOUZA, M. C. M. de. Cafés sustentáveis e denominação de origem: a certificação de qualidade na diferenciação de cafés orgânicos, sombreados e solidários. São Paulo: Tese de Doutorado/FEA/USP, 2006.

VALENTE, A. L. E. F. Algumas reflexões sobre a polêmica Agronegócio versus agricultura familiar. Brasília.Texto para Discussão 29.Brasília: Embrapa Informação tecnológica2008. 78p.

\section{FAMILY FARM MARKETS IN SOUTHERN MINAS GERAIS}

Abstract - The research aims to characterize different realities of family farming, agro-ecological practices and markets in southern Minas Gerais. We studied two agents of socio-economic development in the region, first Free Fair Week in the city of Alfenas - MG, with 516 stallholders in the southern region of Minas, and agroecological production and conventional in the First South Nesting, in Campo do Meio - MG, and difficulty verifying the potentiality of growing coffee agroecosystem in the region who hold $25 \%$ of coffee production in Brazil. The results are from two projects (research and extension) and you can see the difficulty encountered by family farmers in the economic, market and dependence on conventional generation, and technical assistance, lack of technical expertise to transition agroecological the family properties. They exist in the region that promote agroecological production of coffee, but on a small scale, with major problems attracting farmers in this process, the time of transition and economic dependence of conventional methods.

Key-words: Agroecology, family agriculture, development, region.

\section{MERCADOS DE LA AGRICULTURA FAMILIAR EN EL SUR DE MINAS GERAIS}

Resumen - La investigación tiene como objetivo caracterizar diversas realidades de agricultura familiar, prácticas agroecológicas y mercados en el sur de Minas Gerais. Fueron estudiados dos agentes de desarrollo socioeconómico en la región: primero, la feria libre semanal de la ciudad de Alfenas-MG, donde participan 516 feriantes de la región sur de Minas, y la producción agroecológica y convencional en el Asentamiento Primeiro do Sul del municipio Campo do Meio-MG, verificando las dificultades y potencialidades del cultivo de café agroecológico en una región que aporta el 25\% de la producción brasileña de café. Los resultados son provenientes de dos proyectos (extensión e investigación) y se puede constatar en ellos la dificultad encontrada por los agricultores familiares en los aspectos económicos, su dependencia del mercado y la producción convencional, además de la carencia de asistencia técnica por falta de técnicos especializados para hacer la transición agroecológica en propiedades familiares. Existen cooperativas en la región que promueven la producción agroecológica de café, pero en pequeña escala, teniendo grandes dificultades para captar agricultores en este proceso, por el tiempo de transición y de dependencia económica de los métodos convencionales.

Palabras claves: Agroecología, agricultura familiar, desarrollo, región. 